Article

\title{
Long-Term Reliability Evaluation of Silica-Based Coating with Antireflection Effect for Photovoltaic Modules
}

\author{
Kensuke Nishioka ${ }^{1, * \mathbb{C}}$, So Pyay Moe ${ }^{1}$ and Yasuyuki Ota ${ }^{2} \mathbb{C}$ \\ 1 Faculty of Engineering, University of Miyazaki, Gakuen Kibanadai-nishi 1-1, Miyazaki 889-2192, Japan; \\ spyay25@gmail.com \\ 2 Organization for Promotion of Tenure Track, University of Miyazaki, Gakuen Kibanadai-nishi 1-1, \\ Miyazaki 889-2192, Japan; y-ota@cc.miyazaki-u.ac.jp \\ * Correspondence: nishioka@cc.miyazaki-u.ac.jp; Tel.: +81-985-58-7774
}

Received: 8 December 2018; Accepted: 14 January 2019; Published: 15 January 2019

\begin{abstract}
Not all sunlight irradiated on the surface of a photovoltaic (PV) module can reach the cells in the PV module. This loss reduces the conversion efficiency of the PV module. The main factors of this loss are the reflection and soiling on the surface of the PV module. With this, it is effective to have both antireflection and antisoiling effects on the surface of PV modules. In this study, the antireflection and antisoiling effects along with the long-term reliability of the silica-based layer easily coated on PV modules were assessed. A silica-based layer with a controlled thickness and refractive index was coated on the surface of a $\mathrm{Cu}(\mathrm{In}, \mathrm{Ga}) \mathrm{Se}_{2} \mathrm{PV}$ array. The array was exposed outdoors to assess its effects and reliability. As a result of the coating, the output of the PV array increased by $3.9 \%$. The environment of the test site was relatively clean and the increase was considered to be a result of the antireflection effect. Moreover, it was observed that the effect of the coating was maintained without deterioration after 3.5 years. The coating was also applied to a silicon PV module and an effect similar to that of the CIGS PV module was observed in the silicon PV module.
\end{abstract}

Keywords: photovoltaic; coating; antireflection; antisoiling; long-term reliability

\section{Introduction}

With a rising problem in the field of energy, renewable energy sources that are non-reliant on fossil fuels continue to attract attention. Photovoltaics (PVs) was developed as an important and promising technology and has been a top eco-friendly energy solution among the various sustainable energy resources. Single and multi-crystalline silicon PVs are market leaders as first-generation PVs. Currently, thin-film PVs, such as compound semiconductor PVs, play a vital role [1,2].

Not all sunlight irradiated on the surface of the PV module reaches the cells. The loss, from incomplete utilization of sunlight, reduces the conversion efficiency of the PV module. Reflection and soiling on the surface of the PV module, References [3-6], are among the main factors for this loss. Both must be considered in the developing of high-efficiency PV systems. The cover glass of PV modules reflects approximately $4 \%$ of the incident light irradiated to it [7]. Energy losses of the incident light on PV modules occur through the reflection of the air/glass interface due to the difference in the refractive index of the medium [8]. As most PV systems are installed outdoors, it is inevitable for dust and other contaminants to be deposited on the system. Soiling on PV modules prevents light transmittance and decreases the performance of PV systems [9-13]. Therefore, it is relevant to incorporate antireflection and antisoiling effects on the PV module surface to improve the performance of PV systems. 
To overcome common problems in PV systems, transparent coatings that have the ability to suppress reflection and soiling effects spark the interest in PV technologies. Coatings with high transmittance, and antireflection and self-cleaning properties gained significant attention among other types of coatings [14-16]. Silica-based coatings with a nano-sized porous structure have been recognized as a low-cost functional layer with antireflection and antisoiling effects $[17,18]$. By controlling its porosity, the refractive index can be adjusted to perform as an effective antireflection material on PV modules. For coatings, the refractive index and layer thickness were adjusted to increase transmittance [19]. Due to abundant hydroxyl groups in the silica coating, a very thin layer of water can be adsorbed onto the PV module surface. This can prevent localization of electrostatic charges by the electric conductivity of the thin water layer. The electrostatic charges can then be discharged to the environment. Thus, the adhesion of dust can be prevented [20]. Moreover, with the super-hydrophilicity of the coating, dust that adheres to the surface can easily be washed away with a minimal volume of washing water.

Another important key factor of PV systems is long-term reliability. This plays a paramount role in PV plants for a low-levelized cost of energy (LCOE). To retain high efficiency and low LCOE, soiling and reflection must be well-suppressed in PV systems for a long period of time. Practically speaking, it is important to investigate the long-term reliability of the coating on PV modules. This study assessed the antireflection and antisoiling effects along with the long-term reliability of the silica-based layer easily coated on PV modules.

\section{Materials and Methods}

In April 2010, a Cu(In,Ga)Se 2 (CIGS) PV system was installed on the roof of a seven-story building at the University of Miyazaki, Miyazaki, Japan. This system had never been cleaned until 25 December 2014, when cleaning and coating was carried out for the first time since installation. Three arrays (array A, array B, and array C) in the CIGS PV system were used in this study. Table 1 shows the details including the respective treatments applied to each CIGS array. All arrays comprised modules of the same model number and each, with a rated power of $10.2 \mathrm{~kW}$, was composed of 120 modules. Array A was the reference array and did not undergo any treatment. Arrays B and $C$ were cleaned with water using a rotating brush. After the cleaning, a silica-based layer with antireflection and antisoiling effects (EXCEL PURE, Central Automotive Products, Osaka, Japan) was coated on the module surface of array $\mathrm{C}$. The dispersion medium of the coating liquid was composed of a mixture of alcohol and water, and silica having a size of 10 to $100 \mathrm{~nm}$ was dispersed.

Table 1. Details of each CIGS array.

\begin{tabular}{cccc}
\hline Array & Number of Modules & Rated Power $(\mathbf{k W})$ & Treatment \\
\hline A & 120 & 10.2 & No (reference) \\
B & 120 & 10.2 & Cleaning \\
C & 120 & 10.2 & Cleaning and coating \\
\hline
\end{tabular}

The coating was carried out by immersing the coating liquid containing nano-sized silica in a sponge phase resin and scanning the resin on the PV modules, as shown in Figure 1a. Immediately after the coating, the solvent in the coating liquid evaporated and a porous silica layer was formed on the PV modules. The coated layer mainly comprised porous silica that contained many hydroxyl groups that adsorbed water on the surface. To confirm the thickness, the silica layer was coated on a glass substrate with the same method and a cross-sectional image was measured with a transmission electron microscope (JEM-2200FS, JEOL, Tokyo, Japan). The thickness of the coated layer was approximately $150 \mathrm{~nm}$. Figure $1 \mathrm{~b}$ shows the module surface after coating. The color of the coated area evidently turned darker. On 25 December 2014, cleaning and coating were carried out. The arrays were exposed outdoors to assess the effects and the reliability of the coating. Details of this treatment method were reported in Reference [19]. 
The array performance was evaluated using performance ratio $(P R)$ as an indicator. $P R$ was derived as follows:

$$
P R=\frac{\frac{E_{\text {out }}(\mathrm{kWh})}{G I\left(\mathrm{kWh} / \mathrm{m}^{2}\right)}}{\frac{10.2(\mathrm{~kW})[\mathrm{rated} \text { power of a } \mathrm{PV} \text { array }]}{1\left(\mathrm{~kW} / \mathrm{m}^{2}\right)[\mathrm{GI} \text { for rating }]}},
$$

where $E_{\text {out }}$ and GI are the measured energy yield and amount of global solar radiation measured with a pyranometer, respectively.

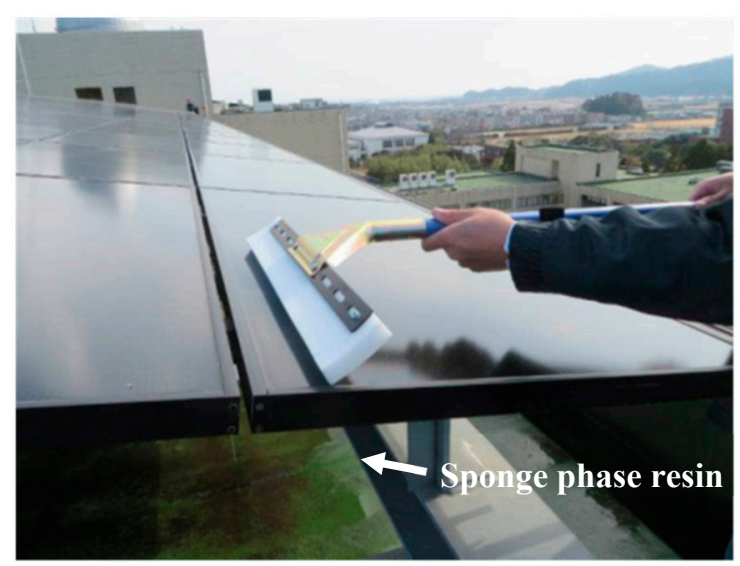

(a)

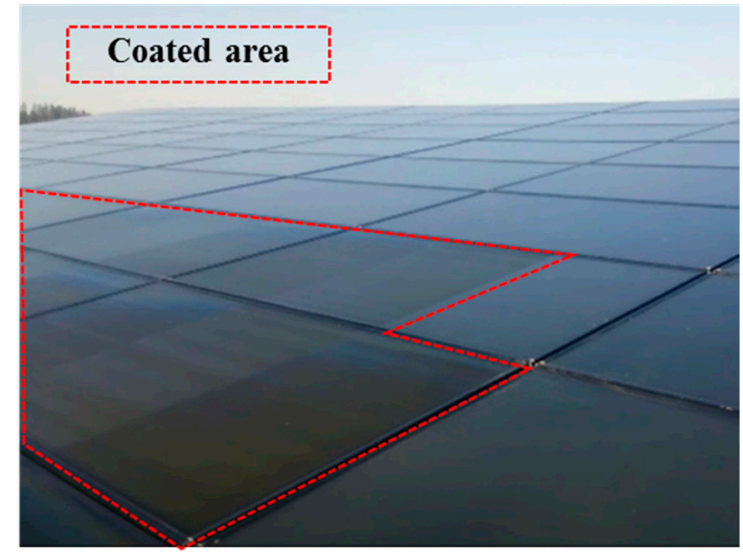

(b)

Figure 1. (a) Coating method using sponge phase resin; (b) surface of the PV modules.

\section{Results and Discussions}

Although the three arrays investigated in this study comprised the same modules, there were some variations in the output between the arrays due to the differences of initial output and installation position. To cancel the initial output difference between the arrays, the daily $P R$ was divided by the average $P R$ for one year (from 25 December 2013, to 24 December 2014) before the treatment. Figure 2a shows the normalized daily PR (NPR) of Arrays B and C. NPRs for Arrays B $\left(\mathrm{NPR}_{\mathrm{B}}\right)$ and C $\left(N P R_{C}\right)$ showed seasonal variation. NPRs have higher values during the winter season (December, January, and February) and lower values during the summer season (July, August, and September). This is because during the summer and winter seasons, the module temperatures are high and low, respectively. $N P R_{B}$ and $N P R_{C}$ are almost the same value before the treatment (25 December 2014). On the contrary, $\mathrm{NPR}_{\mathrm{C}}$ (cleaning and coating) after the treatment was clearly higher than $\mathrm{NPR}_{\mathrm{B}}$ (cleaning only). In both arrays, a slight decrease in the $P R$, due to system degradation, was observed.

To clarify the effects of the treatment on the performance of the PV module, NPR (cleaning only) and $N P R_{C}$ (cleaning and coating) were divided by the normalized daily $P R$ of reference, array A (no treatment). Figure $2 \mathrm{~b}$ shows the twice normalized daily $P R$ of arrays $B$ and $C$. In Figure $2 b$, the seasonal variation and age deterioration, which can be observed in Figure 2a, almost disappeared as a result of the second normalization. From this figure, the effect of the treatment can be clearly assessed. It was found that the twice normalized $P R$ of array B before and after cleaning had little change. This result indicates that the cleaning did not increase the performance of the PV module at the installation site of this study. The environment of the test site was relatively clean because there were no industrial plants or arterial roads near the site and the arrays were installed at a high altitude (the rooftop of a seven-story building). In contrast, the twice normalized $P R$ of array $C$ increased after cleaning and coating. The effect of the coating was clearly observed and the performance of the PV module improved. As the test site was located in a clean environment and the antisoiling effect was not noticeable, this performance improvement was thought to be due to the antireflection effect.

To quantitatively evaluate the effect of the coating, $\mathrm{NPR}_{\mathrm{C}}$ was divided by $\mathrm{NPR}_{\mathrm{B}}$. Figure $2 \mathrm{c}$ shows $\mathrm{NPR}_{C} / \mathrm{NPR}_{\mathrm{B}}$. NPR $\mathrm{C} / \mathrm{NPR}_{\mathrm{B}}$ immediately increased after the coating on 25 December 2014 . The average 
value of $\mathrm{NPR}_{\mathrm{C}} / \mathrm{NPR}_{\mathrm{B}}$ from 25 December 2014, to 30 June 2018 was 1.039. The performance of the PV improved by $3.9 \%$ due to the antireflection effect of the coating.

Moreover, it was found that the effect of the coating was maintained without deterioration even after 3.5 years. In order to reduce the LCOE of PV systems, it is necessary to improve the long-term reliability of the elements constituting it. The coating can be applied via a simple process and with a film thickness as thin as $150 \mathrm{~nm}$. Nevertheless, the coating maintained its effect, for 3.5 years, without deterioration.
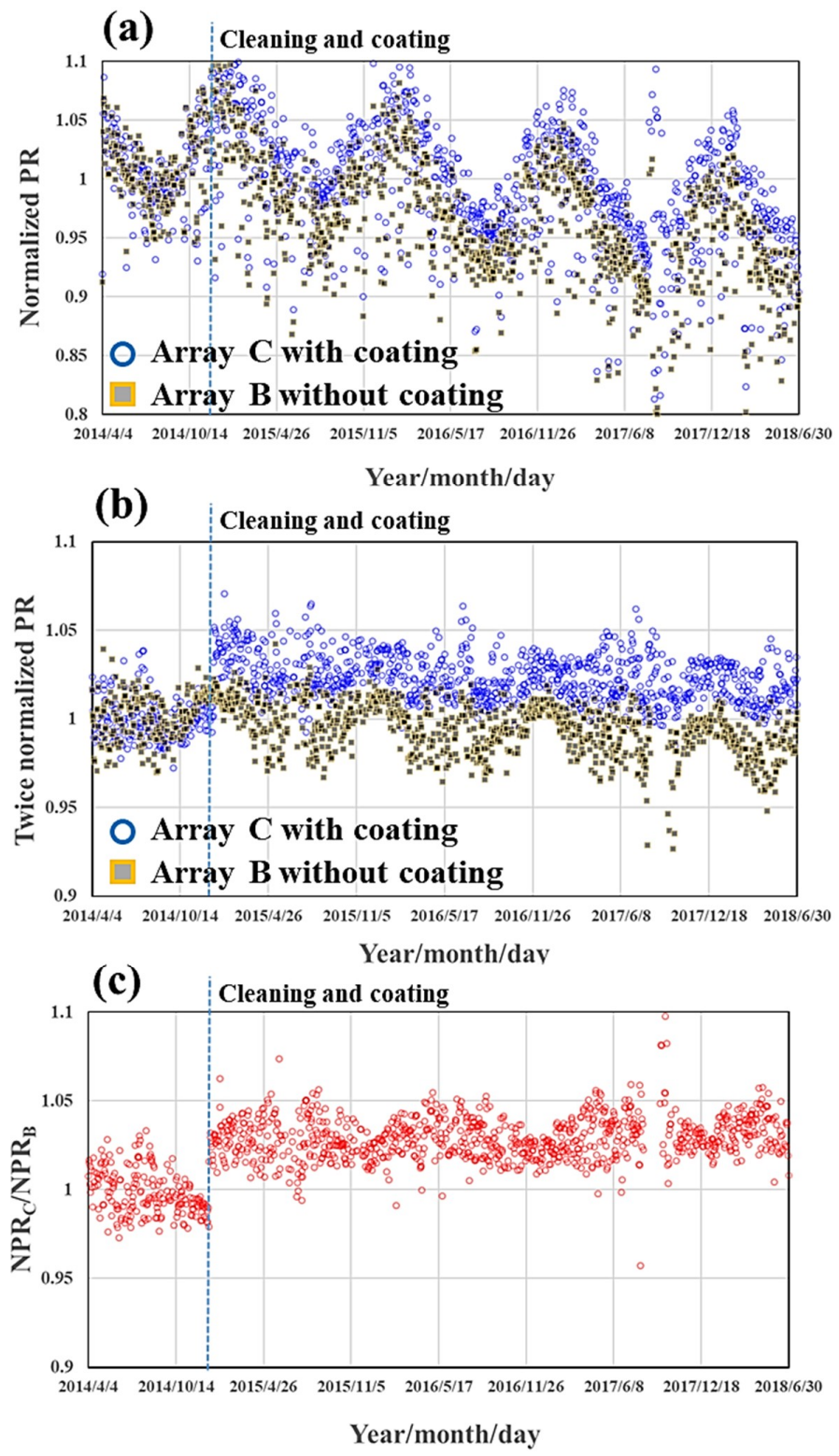

Figure 2. (a) Normalized daily $P R$ of arrays $B\left(N P R_{B}\right)$ and $C\left(N P R_{C}\right)$, (b) twice normalized daily $P R$ of arrays $\mathrm{B}$ and $\mathrm{C}\left(\mathrm{NPR}_{\mathrm{B}}\right.$ and $\mathrm{NPR}_{\mathrm{C}}$ were divided by the normalized daily $P R$ of reference array $\left.\mathrm{A}\right)$, and (c) $\mathrm{NPR}_{\mathrm{C}} / \mathrm{NPR}_{\mathrm{B}}$.

The main reason for reflection is the change in the refractive index from air (with a refractive index of 1) to glass (with a refractive index of 1.5 at $589.3 \mathrm{~nm}$ ). In the case of PV modules, inserting a thin film with a refractive index between air and glass on the cover glass works as an antireflection layer.

Figure 3 shows the refractive index from 200 to $1200 \mathrm{~nm}$ of the coating assessed in this study. The refractive index was measured using a film thickness monitor (FE-3000, Otsuka Electronics, 
Hirakata, Japan). The refractive index of the coating was 1.295 at $589.3 \mathrm{~nm}$. This value is intermediate between air and glass which allowed the coating to act as an antireflection layer.

In this study, the silica-based coating was applied on the CIGS PV modules through a simple process and its effect on PV performance was assessed. The improvement of PV performance was maintained long term, 3.5 years without deterioration. This coating can be applied to other PV modules using glass materials as a cover glass.

Single-crystalline silicon PV modules of the same model number (GT85F, KIS, Saku, Japan) were prepared to be utilized for the assessment. The power of the modules was equal, rated at $90 \mathrm{~W}$. The silica-based layer was coated on the surface of the module. Figure 4 shows the surface of the silicon PV modules after coating. The two modules were coated (modules $X$ and $X^{\prime}$ ) and the other two modules were not coated and act as references (modules $Y$ and $Y^{\prime}$ ). The color of the coated modules (modules $X$ and $X^{\prime}$ ) evidently changed to a darker shade. This was credited to the antireflection effect of the coating. The silicon PV modules were installed and assessed at the University of Miyazaki.

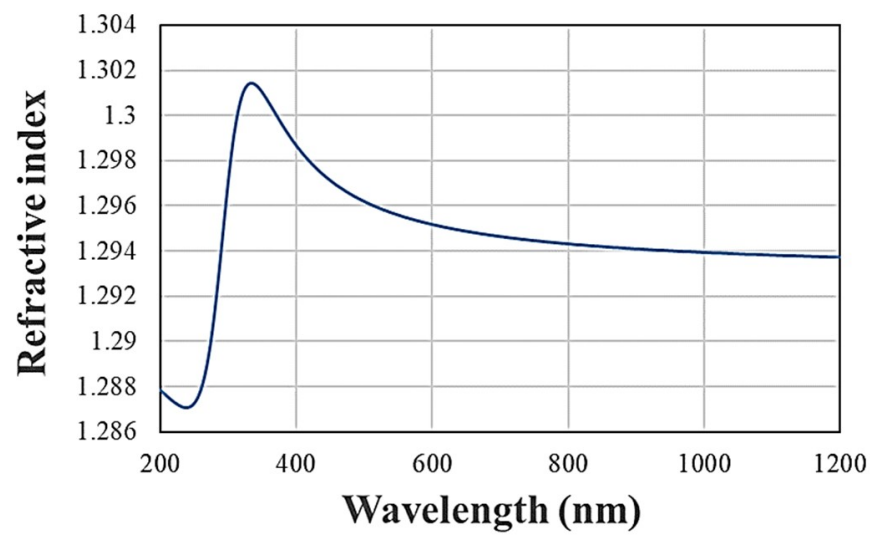

Figure 3. Refractive index as a function of the wavelength for the silica-based coating.

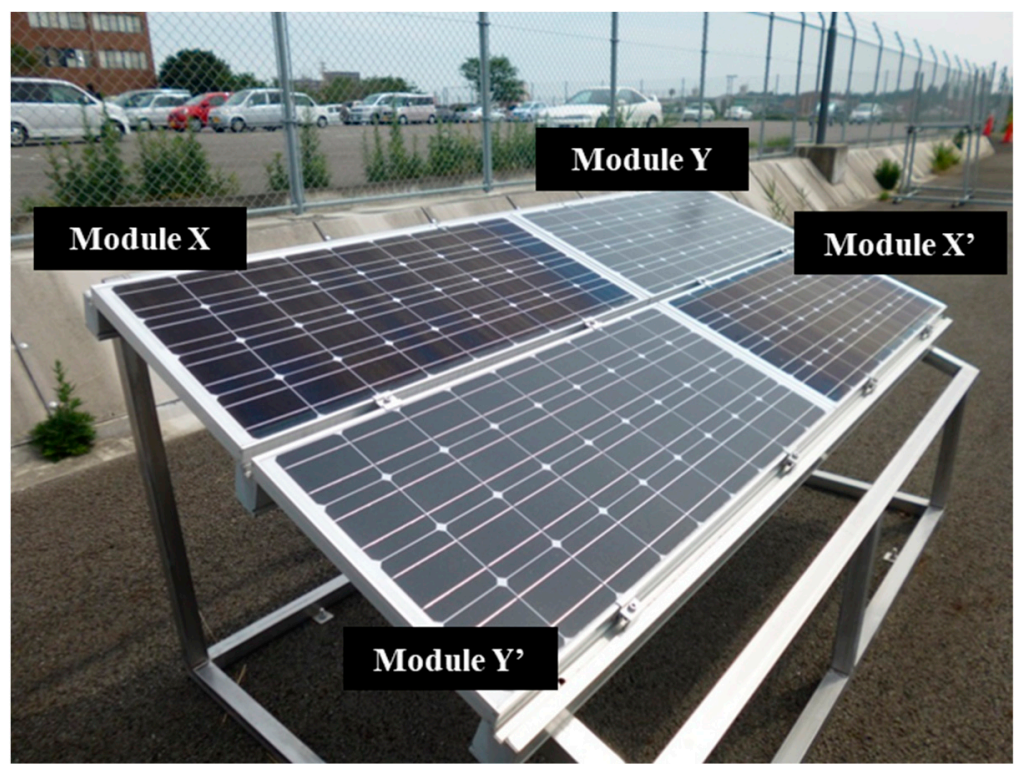

Figure 4. The surface of silicon PV modules. The two modules were coated (modules $X$ and $X^{\prime}$ ) and the other two modules were not coated to act as references (modules $Y$ and $Y^{\prime}$ ).

Figure 5 shows the current-voltage characteristics of module $X$ before and after coating, measured using a solar simulator under standard test conditions. The short-circuit current increased, from 5.56 to $5.74 \mathrm{~A}$ (3.2\% gain). The same coating effect as that of the CIGS PV module was also observed in the silicon PV module. 
The single-crystalline silicon PV modules, with and without coating, were exposed outdoors from 1 December 2015 to assess the effect of the coating. To clarify the effect of the coating, the daily $P R$ of module $X$, with coating $\left(P R_{X}\right)$, was divided by that of module $Y$, without coating $\left(P R_{Y}\right)$. Figure 6 shows the $P R_{X} / P R_{Y}$. The $P R_{X} / P R_{Y}$ increased with an average value of 1.031 (a 3.1\% gain) from 1 December 2015 to 1 April 2016. The environment in which the silicon PV modules were placed was found to be a clean environment with minimal dust and the output gain was considered to be due to the antireflection effect. The coating can be applied not only for CIGS PV modules but also for silicon PV modules.

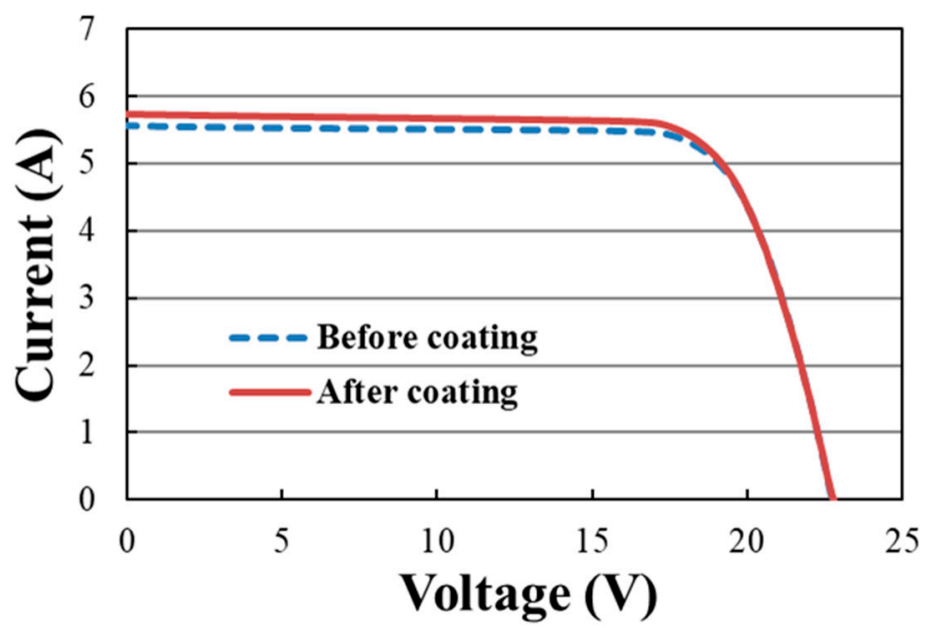

Figure 5. Current-voltage characteristics of module $X$ before and after coating measured using a solar simulator under standard test conditions.

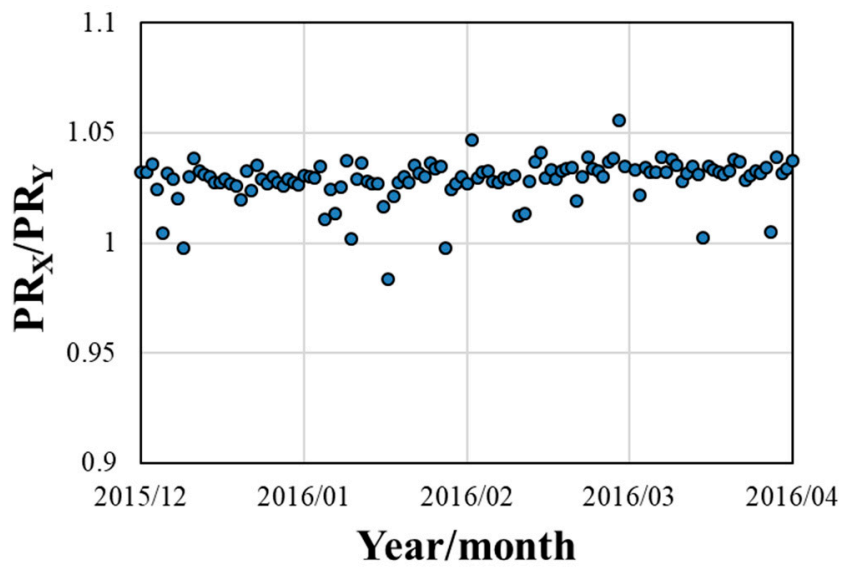

Figure 6. $P R_{X} / P R_{Y}$ ratio versus time.

The cost to apply the coating (cleaning and coating) was 1.5 million JPY for a 1 MW PV system. The yearly output of a 1 MW PV system in Japan is approximately $1000 \mathrm{MWh}$. Assuming that the power selling price is $20 \mathrm{JPY} / \mathrm{kWh}$ and the output gain from the coating is $3.5 \%$, an annual sales increase of 700,000 JPY can be expected. The coating fee will be paid in two years.

Many commercial PV power plants do periodic cleaning to keep energy yields up. The surface damage by the cleaning is becoming a big issue in the PV industry. The durability of the coating to the robot cleaning or other harsh cleaning has not been examined. However, it is expected that the frequency of cleaning and the harshness required for cleaning can be suppressed due to the antisoiling effect of the coating. 


\section{Conclusions}

In this study, the antireflection and antisoiling effects, and long-term reliability of the silica-based layer easily coated on PV modules was assessed. A silica-based layer with antireflection and antisoiling effects was coated on the surface of CIGS PV arrays, and the arrays were exposed outdoors to assess the effects and the reliability of the coating. By controlling the porosity of the coating, the refractive index was adjusted to act as an effective antireflection material on PV modules. The output of the coated PV array showed a 3.9\% increase in the amount of energy collected, confirming that the coating effectively increased the performance of the PV array due to the antireflection effects. Moreover, it was found that the effect of the coating was maintained without deterioration for more than 3.5 years from the date of coating. The environment of the test site was relatively clean, with a minimal amount of dust, as there were no industrial plants or arterial roads near the site location and the arrays were installed at a high altitude (on the rooftop of the seven-story building). The antisoiling effect of the coating was not considered as the PV array was not sufficiently dirty to exert a significant influence on the performance of the PV array. The coating was also applied to a silicon PV module and the same effect as that of the CIGS PV module was seen.

Author Contributions: Conceptualization, K.N.; Methodology, K.N. and Y.O.; Analysis, K.N., S.P.M. and Y.O.; Validation, K.N. and S.P.M.; Writing-Original draft preparation, K.N.; Writing-Review and editing, K.N.; Supervision, K.N.

Funding: This research received no external funding.

Acknowledgments: We would like to thank Satoshi Miyai of Central Automotive Products for valuable discussions.

Conflicts of Interest: The authors declare no conflict of interest.

\section{References}

1. Kushiya, K. CIS-based thin-film PV technology in solar frontier K.K. Sol. Energy Mater. Sol. Cells 2014, 122, 309-313. [CrossRef]

2. Kushiya, K. Key near-term R\&D issues for continuous improvement in CIS-based thin-film PV modules. Sol. Energy Mater. Sol. Cells 2009, 93, 1037-1041. [CrossRef]

3. Elminir, H.K.; Ghitas, A.E.; Hamid, R.H.; El-Hussainy, F.; Beheary, M.M.; Abdel-Moneim, K.M. Effect of dust on the transparent cover of solar collectors. Energy Convers. Manag. 2006, 47, 3192-3203. [CrossRef]

4. García, M.; Marroyo, L.; Lorenzo, E.; Pérez, M. Soiling and other optical losses in solar-tracking PV plants in navarra. Prog. Photovolt. 2011, 19, 211-217. [CrossRef]

5. Piliougine, M.; Cañete, C.; Moreno, R.; Carretero, J.; Hirose, J.; Ogawa, S.; Sidrach-de-Cardona, M. Comparative analysis of energy produced by photovoltaic modules with anti-soiling coated surface in arid climates. Appl. Energy 2013, 112, 626-634. [CrossRef]

6. Paudyal, B.R.; Shakya, S.R. Dust accumulation effects on efficiency of solar PV modules for off grid purpose: A case study of Kathmandu. Sol. Energy 2016, 135, 103-110. [CrossRef]

7. Priyadarshini, B.G.; Sharma, A.K. Design of multi-layer anti-reflection coating for terrestrial solar panel glass. Bull. Mater. Sci. 2016, 39, 683-689. [CrossRef]

8. Arabatzis, I.; Todorova, N.; Fasaki, I.; Tsesmeli, C.; Peppas, A.; Li, W.X.; Zhao, Z. Photocatalytic, self-cleaning, antireflective coating for photovoltaic panels: Characterization and monitoring in real conditions. Sol. Energy 2018, 159, 251-259. [CrossRef]

9. El-Shobokshy, M.S.; Hussein, F.M. Effect of dust with different physical properties on the performance of photovoltaic cells. Sol. Energy 1993, 51, 505-511. [CrossRef]

10. El-Shobokshy, M.S.; Hussein, F.M. Degradation of photovoltaic cell performance due to dust deposition on to its surface. Renew. Energy 1993, 3, 585-590. [CrossRef]

11. Mastekbayeva, G.A.; Kumar, S. Effect of dust on the transmittance of low density polyethylene glazing in a tropical climate. Sol. Energy 2000, 68, 135-141. [CrossRef]

12. Kalogirou, S.A.; Agathokleous, R.; Panayiotou, G. On-site PV characterization and the effect of soiling on their performance. Energy 2013, 51, 439-446. [CrossRef] 
13. Mani, M.; Pillai, M. Impact of dust on solar photovoltaic (PV) performance: Recent status, challenges and recommendations. Renew. Sustain. Energy Rev. 2010, 14, 3124-3131. [CrossRef]

14. Nabemoto, K.; Sakurada, Y.; Ota, Y.; Takami, K.; Nagai, H.; Tamura, K.; Araki, K.; Nishioka, K. Effect of anti-soiling layer coated on poly(methyl methacrylate) for concentrator photovoltaic modules. Jpn. J. Appl. Phys. 2012, 51, 10ND11. [CrossRef]

15. Sueto, T.; Ota, Y.; Nishioka, K. Suppression of dust adhesion on a concentrator photovoltaic module using an anti-soiling photocatalytic coating. Sol. Energy 2013, 97, 414-417. [CrossRef]

16. Hanaei, H.; Assadi, M.K.; Saidur, R. Highly efficient antireflective and self-cleaning coatings that incorporate carbon nanotubes (CNTs) into solar cells: A review. Renew. Sustain. Energy Rev. 2016, 59, 620-635. [CrossRef]

17. Lu, X.; Wang, Z.; Yang, X.; Xu, X.; Zhang, L.; Zhao, N.; Xu, J. Antifogging and antireflective silica film and its application on solar modules. Surf. Coat. Technol. 2011, 206, 1490-1494. [CrossRef]

18. Thompson, C.S.; Fleming, R.A.; Zou, M. Transparent self-cleaning and antifogging silica nanoparticle films. Sol. Energy Mater. Sol. Cells 2013, 115, 108-113. [CrossRef]

19. Ota, Y.; Ahmad, N.; Nishioka, K. A 3.2\% output increase in an existing photovoltaic system using an antireflection and anti-soiling silica-based coat. Sol. Energy 2016, 136, 547-552. [CrossRef]

20. Horiuchi, Y.; Yamashita, H. Design of mesoporous silica thin films containing single-site photocatalysts and their applications to superhydrophilic materials. Appl. Catal. A 2011, 400,1-8. [CrossRef]

(C) 2019 by the authors. Licensee MDPI, Basel, Switzerland. This article is an open access article distributed under the terms and conditions of the Creative Commons Attribution (CC BY) license (http://creativecommons.org/licenses/by/4.0/). 